\title{
New pistachio varieties show promise for California cultivation
}

\author{
by Craig E. Kallsen, Dan E. Parfitt, \\ Joseph Maranto and Brent A. Holtz
}

\section{California pistachio growers have} long relied on a single female ('Kerman') and single male ('Peters') cultivar. Despite their benefits, these cultivars present important production and marketing concerns. To evaluate new varieties for the pistachio industry, we conducted the first randomized and replicated pistachio variety trials in the San Joaquin Valley, where most U.S. pistachios are grown. After more than a decade of scientific evaluation, several varieties new to California (such as 'Kalehghouchi') or the world (such as 'Golden Hills') demonstrated commercial potential for the California pistachio industry and would complement the production characteristics of 'Kerman'.

$\mathrm{P}$ istachio production has expanded rapidly in California, but varietal options for growers have not. In 2006, California growers harvested 112,500 acres of pistachio and planted another 40,100 nonbearing acres (CPC 2007; USDA 2007). In 2005 and 2006, the average yearly value of California's pistachio crop was approximately $\$ 518$ million (CPC 2007). Unlike most crops, the California pistachio industry is almost completely reliant on a single female cultivar, 'Kerman', and a pollinating male, 'Peters', to produce pistachios. Aside from the potential genetic vulnerability to pests that is often associated with cultivating a single female cultivar, other problems became more apparent as pistachio acreage increased.

Alternate bearing is a prominent characteristic of pistachio, 'Kerman' included. The onset of alternate bearing in pistachio is a function of age. Fruit and nut tree age is typically measured

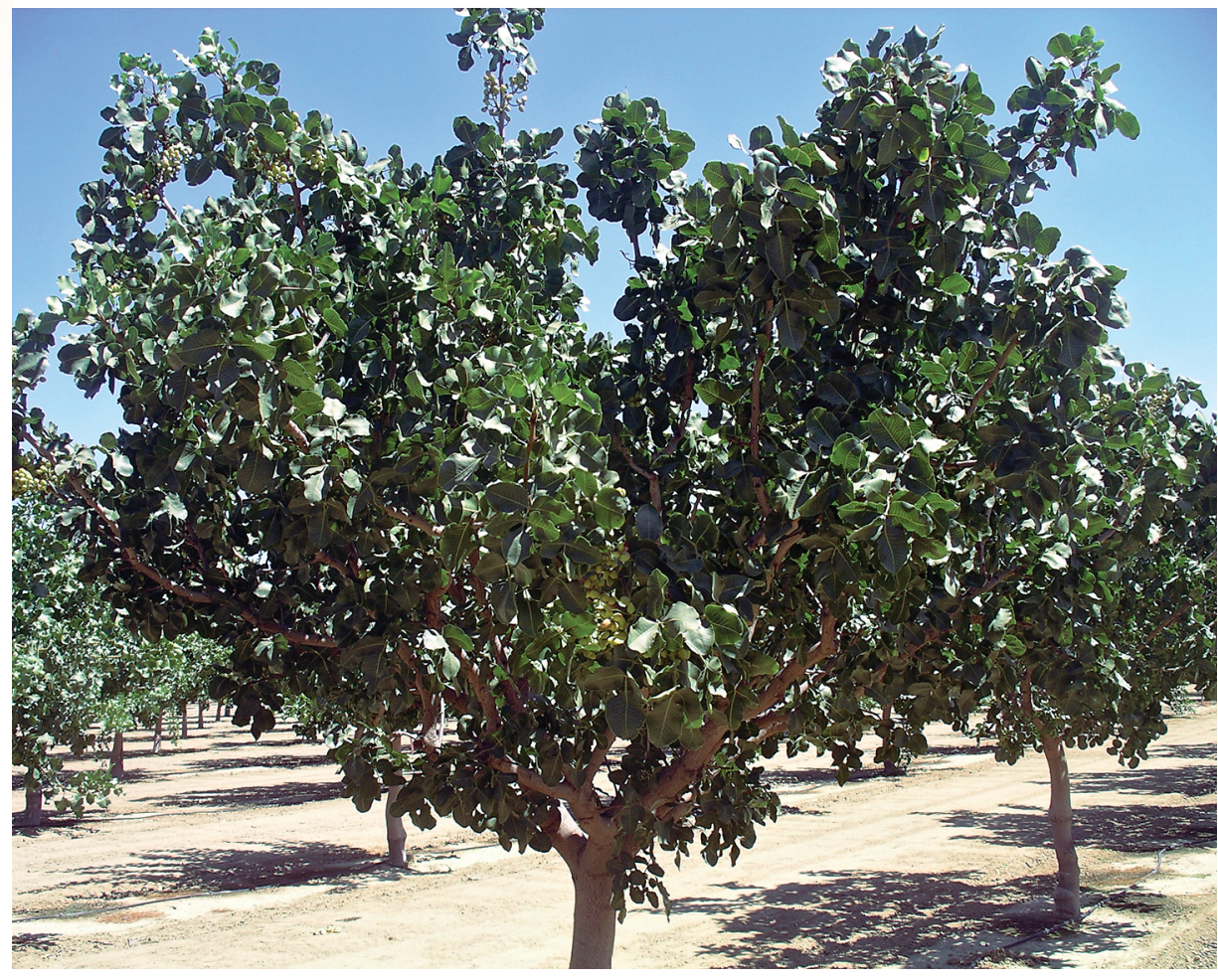

The California pistachio industry, which grows more than $90 \%$ of the nation's crop, has historically been dominated by a single female variety, 'Kerman'. UC researchers conducted the first randomized and replicated pistachio trials, and two new female and one male variety were released in 2005. 'Golden Hills', shown at 9 years of age in June 2006, is similar to 'Kerman' but with a larger number of somewhat thinner scaffold branches.

in "leaves" as opposed to years: the age of a tree at planting is 1st leaf, and a tree does not become 1 year old until 2nd leaf. Usually, beginning in 10th-leaf trees (i.e., 9-year-old trees), 'Kerman' enters into an alternate-bearing cycle with a low-yielding year followed by a highyielding year. For reasons that are not clear (weather is suspected of triggering the cycle), the majority of acreage in the San Joaquin Valley, where over $90 \%$ of the nation's pistachio crop is located, becomes synchronized so that production for an entire year is high or low, regardless of when a particular 'Kerman' tree (or orchard) was planted.

Since 'Kerman' is the dominant female cultivar grown in California, and most production acreage is located in a relatively limited region with similar growing conditions, the entire crop matures within a brief time period. Harvest begins in early September and ends by the second week in October. Most trees in the San Joaquin Valley are harvested within a 2- to 3-week period in most years. During "on" or highyielding years, adequate harvest equipment, labor, processing and storage facilities are not available, while in "off" or low-yielding years some of these resources remain unused.

This is a particular problem for processing plants that hull, sort, dry, roast, store and package the crop. Processing capacity has an investment cost and if it is not used efficiently that cost must be absorbed by the processor-investor and passed along to the grower in the form of lower payments for the crop and to the consumer as higher prices for the product. Early- and late-maturing cultivars are available for other nut crops grown in California, distributing the harvest across a longer time period. For example, the commercial almond (Prunus dulcis) harvest in the San Joaquin Valley typically begins with the 'Nonpareil' cultivar about Aug. 1 and ends with the 'Fritz' and 

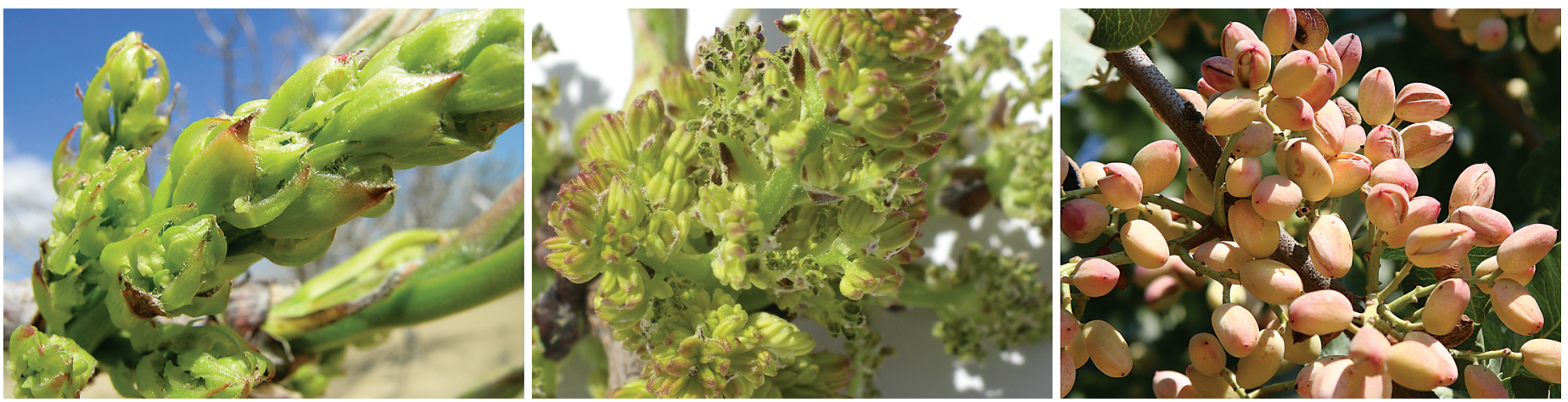

As with most wind-pollinated plants, pistachio flowers are small and not showy, as with, left, the female 'Golden Hills' and, center, male 'Randy'. In California, male trees are commonly planted as every fifth tree in every fifth row to provide adequate pollination. Right, a 'Golden Hills' nut cluster demonstrates greater development of red color in the hull than 'Kerman'.

'Monterey' cultivars in mid-October. Reliance on a single, alternate-bearing cultivar has complicated pistachio marketing efforts, with prices declining in heavy-bearing years and increasing in low-yielding years.

While 'Kerman' has been a dependable producer of quality pistachios in California for 50 years, it also has some negative characteristics. For example, a load of 'Kerman' nuts arriving from the field to the processing plant at harvest includes a relatively high percentage of nuts with no kernels (called blank nuts) and unsplit nuts containing edible kernels (called edible, closed, in-shell nuts). A typical load of pistachio nuts delivered to a San Joaquin Valley processing plant may contain approximately $10 \%$ blank and $15 \%$ edible, closed, in-shell nuts.

The pistachio industry has attempted to address alternate-bearing, blank and closed-shell nuts through cultural practices such as pruning and irrigation management. Pruning can be conducted to reduce the nut bearing potential of the tree through leaf canopy reduction in a given year, which can mitigate the alternate-bearing cycle over a period of years (Ferguson et al. 1995). Deficit irrigation of the tree from May to mid-June has been shown to increase the percentage of nuts that split without reducing yield (Goldhamer and Beede 2004). California 'Kerman' growers are using both of these practices, developed by University of California researchers.

\section{Pistachio industry boost}

Pistachio was first introduced to California more than a century ago near Sacramento (Crane and Maranto
1988). The commercially grown pistachio species in California, Pistacia vera L., is native to a wide area of Central Asia, including parts of northeastern Iran, northern Afghanistan, southern Turkmenistan, and southeastern Uzbekistan, Tajikistan and Kyrgyzstan (Zohary 2006). This pistachio species is well adapted to Mediterranean climates typified by long, hot, dry summers and relatively cool winters.

Historically, Iran has been and continues to be the world leader in pistachio production, and in the 1960s competition from U.S. growers with the Iranian red-dyed pistachio nut was minimal. However, this changed with the imposition of U.S. embargoes on all Iranian exports as a result of the Iranian hostage crisis from 1979 to 1981. An unintended consequence of this embargo was the opportunity to establish a world-class pistachio industry in California. The California industry now produces high yields of excellent quality nuts in demand worldwide, and supplies over $99 \%$ of pistachios grown and consumed in the United States.

Most of this production occurs on deep, boric and calcareous soils of the southwestern San Joaquin Valley, where summers are characterized by hot temperatures, low humidity, low precipitation and light winds.

\section{Dependence on one cultivar}

The female cultivar 'Kerman', named in 1952, was produced from seed imported from Iran in 1929 through a U.S. Department of Agriculture (USDA) importation and evaluation program in Chico. 'Kerman' was introduced to growers in trials beginning in 1957. The 'Peters' male is reported to have been selected and named by A.B. Peters, a pistachio grower near Fresno, in the early 1900s. Pistachio trees are dioecious, which means female (nut-producing) flowers and male (pollen-producing) flowers are borne on different cultivars. Pistachio is windpollinated, and both male and female trees are required to produce nuts. The flowering period of 'Peters' overlaps with that of 'Kerman' well; few growers found other pollinating varieties necessary, and few other choices existed.

Through the 1980s, the state's relatively small pistachio industry expanded slowly and there was little interest or demand for new cultivars. A few growers had small acreages of cultivars such as 'Aria', 'Bronte', 'Red Aleppo', 'Trabonella'

\section{A single negative} characteristic can render an otherwise useful variety with many exceptional

\section{characteristics unsuitable for commercial production.}

and 'Kalehghouchi', many of which originally came to California from the Mediterranean area and the Middle East before 'Kerman' was available. 'Kerman' proved well-adapted to the needs of the small pistachio industry, and there was little incentive for researchers to evaluate new or existing cultivars against it in randomized, replicated trials prior to the rapid expansion of the industry. Without the scientific evaluation of yield and nutquality characteristics, growers were understandably hesitant to accept the 
UC-bred 'Golden Hills' and 'Lost Hills', and the additional Iranian cultivars

'Kalehghouchi' and 'Aria'.

Bloom timing. Since male and female flowers are located on different trees in pistachio, finding cultivars with overlapping bloom periods is critical for nut production. In these experiments, the approximate date of full bloom was determined by visiting the two trials at intervals of 3 to 4 days during bloom. The pistachio inflorescence is composed of a central axis, called the rachis, with lateral branches. These lateral branches have a terminal flower with a variable number (usually less than 25) of lateral flowers. Full bloom was defined as the date when trees had the maximum number of open flowers. Since each blooming inflorescence may contain several hundred flowers, and all inflorescences on the tree are not in bloom at the same time, the "full bloom" date represents the statistical mode of all the individual flower bloom dates.

The flowering periods for the female cultivars 'Golden Hills' and 'Lost Hills' overlapped well with those of the male cultivar 'Randy'. Also, full bloom for these cultivars was approximately 1 week earlier than that for 'Kerman' and 'Peters', the female and male cultivars most commonly planted in California today (table 2). Compared to 'Peters', 'Randy' had highly viable and durable pollen as measured by hanging drop slides in 1996. Initial pollen viability was 75\% for 'Randy' compared to $45 \%$ for 'Peters', and pollen viability after 29 days in storage was 35\% for 'Randy' compared to 10\% for Peters.

Like the UC-bred female cultivars, the Iranian variety 'Kalehghouchi' bloomed earlier than 'Kerman' and the 'Randy' male overlapped this bloom period well (table 2). However, because the Iranian variety 'Aria' occasionally bloomed before 'Randy', earlier-blooming experimental male selections were also included in this trial to ensure that the earlier-blooming 'Aria' trees had sufficient pollen for adequate fruit-set.

Nut yield and quality. Nuts were knocked from 6th- through 8th-leaf trees with mallets and poles onto tarps, and were shaken from trees older than 8th leaf with mechanical shakers and catching frames. During harvest, two or three 20-pound (9.1 kilogram) samples were collected randomly from the harvest bins in each replication. These samples were transported to a pistachio processor on harvest day to begin nut quality evaluations. At the huller, each of the collected samples was weighed fresh, hulled, dried and evaluated by USDA-trained inspectors.

The pistachio nut consists of an outer hull that is removed early in processing, an outer shell, and the kernel or nutmeat. Evaluations consisted of quantifying the percentages of four categories of pistachios: (1) edible, split, in-shell nuts; (2) shelling stock (split nuts with a damaged shells that must be removed, or kernels that have separated from their shells); (3) closed-shell nuts (unsplit nuts with an edible kernel); and (4) culls (nuts with serious defects such as lacking a kernel or having insect damage) in each of the previous three categories. Culls were not included in yield determinations.
Sample results were averaged and used to calculate the percentage by weight, adjusted to $5 \%$ moisture on a per acre basis of the following: (1) total nut yield (total weight of shells and kernels); (2) edible yield (total weight of edible, split, in-shell nuts plus the weight of kernels from shelling stock and closed-shell nuts); and (3) edible, split, in-shell nuts. Nuts are typically stored at 5\% moisture and growers are paid based on the edible yield adjusted to this level of moisture in the nuts. Drying all sample nuts to precisely 5\% moisture for calculation purposes is impossible, and tables are used to adjust the yields appropriately for small variations plus or minus the required $5 \%$ moisture. Data were analyzed using a repeated measures ANOVA design. In addition to significant cultivar differences, significant differences in year and year-by-cultivar interactions were

TABLE 2. Estimated full bloom date for pistachio varieties evaluated in northwestern Kern County

\begin{tabular}{lccccc}
\hline Cultivar & 2003* & 2004 & 2005 & 2006 & 2007 \\
\hline Kerman & April 5 & April 2 & April 1 & May 1 & April 1 \\
Golden Hills & March 31 & March 29 & March 26 & April 24 & March 26 \\
Lost Hills & March 30 & March 27 & March 24 & April 28 & March 28 \\
Aria & March 29 & March 23 & March 20 & April 19 & March 23 \\
Kalehghouchi & March 31 & March 24 & March 24 & April 28 & March 23 \\
Peters (male) & April 2 & April 1 & April 1 & May 1 & April 1 \\
Randy (male) & March 29 & March 23 & March 24 & April 28 & March 25 \\
\hline
\end{tabular}

* All trees in the two experimental trials were accidentally treated with dormant petroleum oil that advanced bloom in 2003.

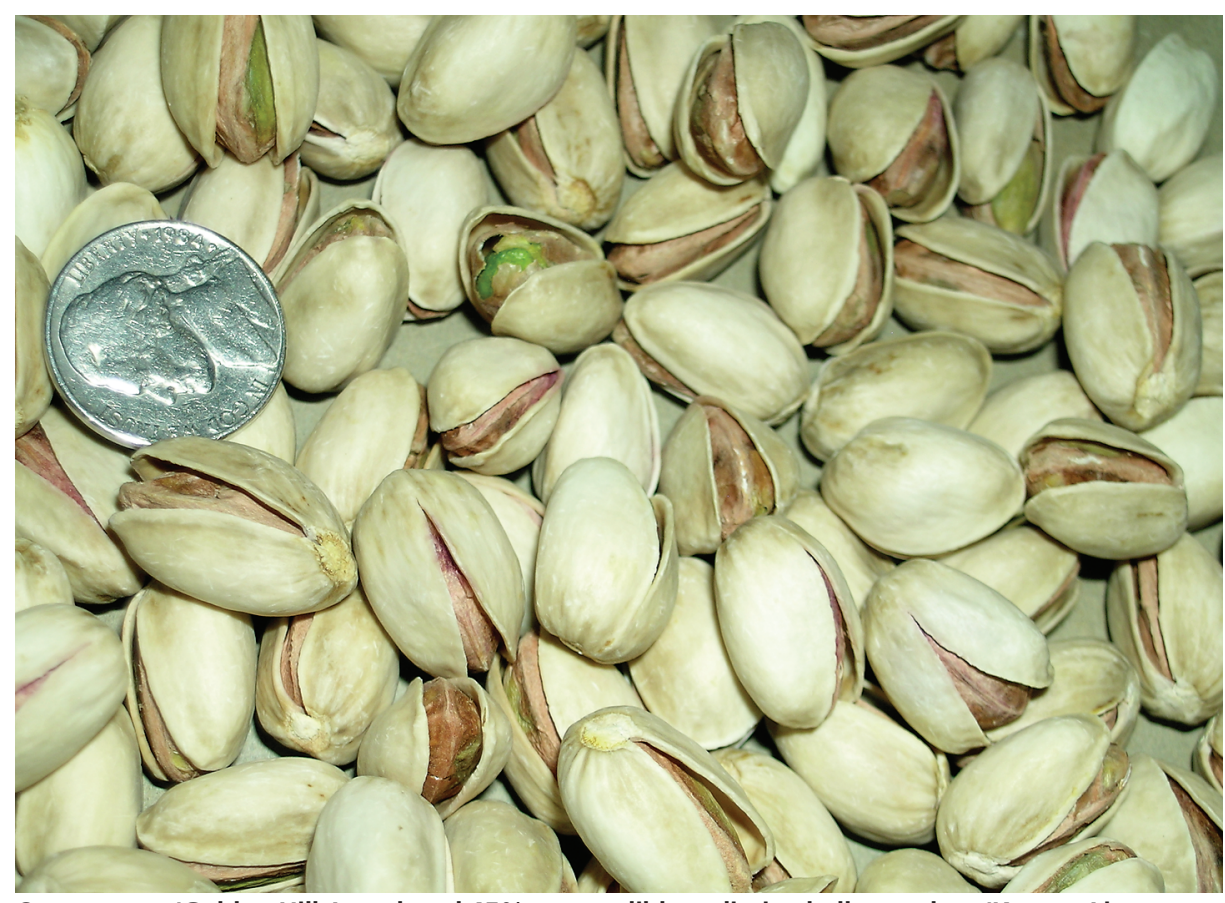

On average, 'Golden Hills' produced $45 \%$ more edible, split, in-shell nuts than 'Kerman' in every year of the trial. Acreage of this new variety is slowly increasing in the San Joaquin Valley. 


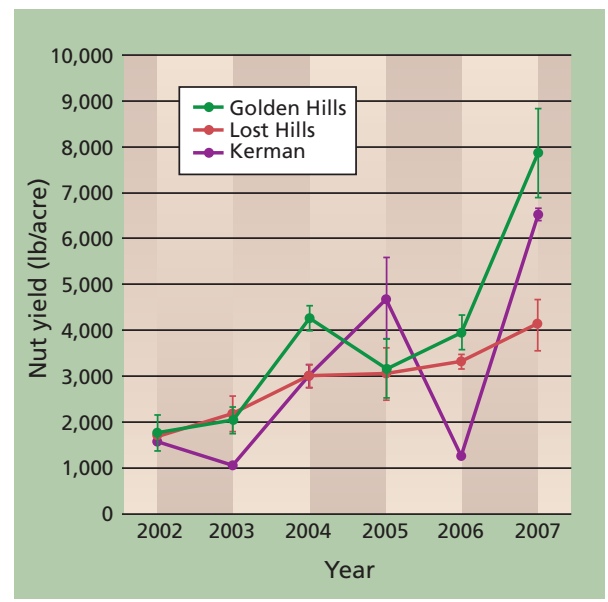

Fig. 1. Yield of nuts, minus culls and adjusted to $5 \%$ moisture, in northwestern Kern County for 6 th- through 11th-leaf pistachio trees. Error bars represent \pm one standard error of the mean $(\mathrm{kg} / \mathrm{ha}=\mathrm{lb} / \mathrm{acre} \times 1.1208)$.

noted in the analyses as would be expected in alternate-bearing trees that were increasing in maturity and consequently yield.

In the UC-bred cultivar trial, yield of 'Golden Hills' was greater than that of 'Kerman' and 'Lost Hills' by all three measures (fig. 1, table 3). Compared to 'Kerman', 'Golden Hills' produced 27\% more total nut yield, 35\% more edible weight, and $45 \%$ more edible, split, inshell nut weight on average every year from 6th through 11th leaf. The greatly reduced alternate bearing of 'Lost Hills' from 2002 through 2007 differentiated this cultivar from the others evaluated in these trials (fig. 1). In the Iranian variety trial, 'Kerman' and 'Kalehghouchi' had similar yields, while 'Aria' produced less than either of these cultivars (table 3).

The higher percentages of edible, split, in-shell nuts from 'Golden Hills' and 'Kalehghouchi' compared to 'Kerman' also means fewer shells and culls generated during processing, which means less waste for processing plants to dispose of. Compared to 'Kerman', the average annual percentage of a load of pistachios brought in from the field that was edible weight was 4.6\% higher for 'Golden Hills' and 3.9\% higher for 'Kalehghouchi' (table 3).

Earlier harvests. Perhaps the most valuable characteristic of 'Golden Hills' and 'Lost Hills' in these trials was their early harvest dates. Nuts of 'Golden Hills', 'Lost Hills' and 'Aria' were ready for harvest approximately 2 weeks or more earlier, on average,

TABLE 3 . Average characteristics of UC (6th through 11th leaf) and Iranian (5th and 7th through 10th leaf) varieties in northwestern Kern County

\begin{tabular}{|c|c|c|c|}
\hline \multicolumn{4}{|l|}{ UC cultivars } \\
\hline Nut yield (Ib/acre)* & $3,036 a+$ & $3,849 \mathrm{~b}$ & $2,895 a$ \\
\hline Edible yield (Ib/acre) & $2,712 \mathrm{a}$ & $3,655 a$ & $2,763 a$ \\
\hline Edible, split, in-shell yield (lb/acre) & $2,389 a$ & $3,460 \mathrm{~b}$ & $2,631 \mathrm{a}$ \\
\hline Edible yield $(\%) \ddagger$ & $30.2 \mathrm{a}$ & $34.8 \mathrm{c}$ & $32.6 b$ \\
\hline Edible, split, in-shell (\%)§ & $67.8 a$ & $84.6 b$ & $85.5 b$ \\
\hline Total insect damage (\%)§ & $1.8 \mathrm{~b}$ & $0.0 a$ & $0.2 \mathrm{a}$ \\
\hline Loose shells and kernels (\%)§ & $0.5 a$ & $0.6 a$ & $3.20 \mathrm{~b}$ \\
\hline Individual nut weight (grams) & $1.24 a$ & $1.26 a$ & $1.47 \mathrm{~b}$ \\
\hline Harvest readiness date & Sept. 12 & Aug. 29 & Aug. 30 \\
\hline \multicolumn{4}{|l|}{ Iranian cultivars } \\
\hline Characteristic & Kerman & Kalehghouchi & Aria \\
\hline Nut yield (Ib/acre)* & $2,470 b$ & $2,539 \mathrm{~b}$ & $2,162 a$ \\
\hline Edible yield (Ib/acre) & $2,276 b$ & $2,430 \mathrm{~b}$ & $2,026 a$ \\
\hline Edible, split, in-shell yield (Ib/acre) & $2,080 a$ & $2,334 b$ & $1,880 a$ \\
\hline Edible yield (\%)‡ & $29.4 a$ & $33.3 \mathrm{~b}$ & $30.2 a$ \\
\hline Edible, split in-shell (\%)§ & 74.4a & $84.8 c$ & $77.2 \mathrm{~b}$ \\
\hline Total insect damage $(\%) \S$ & $1.3 a$ & $1.1 \mathrm{a}$ & $0.4 a$ \\
\hline Loose shells and kernels (\%)§ & $0.5 a$ & $1.4 \mathrm{~b}$ & $5.2 \mathrm{c}$ \\
\hline Individual nut weight (grams) & $1.23 a$ & $1.44 \mathrm{c}$ & $1.35 \mathrm{~b}$ \\
\hline Harvest readiness date & Sept.16 & Sept. 14 & Sept. 1 \\
\hline \multicolumn{4}{|c|}{ * $\mathrm{lb} / \mathrm{acre} \times 1.1208$ = kg/ha. } \\
\hline \multicolumn{3}{|c|}{$\begin{array}{l}\text { † Values within the same row for each trial followed by different letters } \\
\text { are significantly different at } P \leq 0.05 \text { by Fisher's protected LSD test. }\end{array}$} & \\
\hline
\end{tabular}

than those of 'Kerman' (table 3). This earlier nut maturity increased the San Joaquin Valley harvest period by approximately $30 \%$. From 6 th through 10th leaf, 'Kalehghouchi' was ready for harvest, on average, 3 days earlier than 'Kerman'. Earlier harvest would increase the efficiency of the industrywide pistachio harvest by extending the harvest season and reducing peak demand for labor, harvesting equipment and nut processing facilities.

An earlier harvest can also reduce insect damage. Navel orangeworm typically causes the largest percentage of total insect damage that reaches the processing plant (see page 24). Navel orangeworm damage has the potential to increase greatly with each reproductive cycle in infested orchards. A fourth generation of this pest is often present before the 'Kerman' harvest, while 'Golden Hills' and 'Lost Hills' are harvested prior to its emergence. In the Kern County trial, both UC cultivars had less insect damage than 'Kerman', while 'Kalehghouchi' and 'Aria' had levels similar to 'Kerman' (table 3).

Shell-hinge strength and nut size. A successful pistachio cultivar will produce a nut that is split enough to open easily, yet has sufficient shellhinge strength to prevent it from falling apart in hulling or later in storage, transportation or the retail store. A crude indicator of shell-hinge strength is the percentage of loose shells and kernels in nut samples taken at harvest. Loose shells and kernels result from nuts that fall apart during or after hulling but before packaging. Based on this measure, 'Golden Hills' and 'Kerman' had similar hinge strengths, even though 'Golden Hills' had a higher split-nut percentage (table 3).

While many consumers consider bigger as being better, larger nuts tend toward lower shell-hinge strength than smaller nuts. The nuts of 'Aria', 'Kalehghouchi' and 'Lost Hills' were larger than those of 'Kerman' (table 3). 'Kalehghouchi', characterized by a high edible split-nut percentage, showed only slightly reduced shell-hinge strength compared to 'Kerman'. However, poorer shell-hinge strength is more characteristic of 'Lost Hills' and 'Aria', which could potentially limit their commercial potential and acceptability at some nut processing plants.

Increasingly, shelled kernels are being sold as a product. However, in 
modern processing plants a larger percentage of kernels is recovered from shelling closed-shell nuts than from split nuts that fall apart during processing, where kernels are more likely to be lost or damaged during hulling.

Tree structure and growth. 'Golden Hills' produced more upright branches than 'Kerman' and 'Lost Hills', and as a result could potentially produce more flowers and nuts. Branches of 'Kalehghouchi' grew more vigorously than 'Kerman' during the growing season and, especially when young, produced numerous long, unbranched, lowhanging shoots (i.e., lanky growth) that had to be pruned prior to mechanical harvest. 'Aria' produced large clusters of nuts near the ends of branches, making the trees more difficult to prune and shake efficiently, and the nuts more subject to sunburning. 'Kalehghouchi' trunk diameter increased faster than that of 'Kerman', which may make this cultivar more difficult to mechanically shake as time passes. All of the varieties evaluated demonstrated a greater ratio of trunk-to-rootstock diameter than 'Kerman'.

\section{Future cultivar development}

Identifying suitable existing cultivars in other parts of the world may be difficult because pistachios are grown very differently elsewhere. The California industry produces pistachios with relatively abundant and goodquality irrigation water and fertilizers, excellent soils, and mechanized pruning and harvesting. The Central Valley climate is also characterized by winters in which the duration of cold temperatures is not sufficient to promote the rest period necessary for uniform flowering in the spring of some varieties (Ferguson 2006).

In contrast, because pistachios are still relatively undeveloped genetically compared to other tree and row crops, there is excellent potential for developing new cultivars to benefit the California industry. Breeding should remain an important component of any crop industry's research program. In most crops, new cultivars contribute significantly to insect and disease resistance. For example, the California pistachio industry would probably not exist without Verticillium wilt resistance, which was discovered in P. integerrima during rootstock trials. In addition, some pistachio varieties have varying resistance to Alternaria leaf blight, a serious disease of this crop. The possibilities of incorporating this leaf blight resistance into commercial pistachio cultivars remains undeveloped (Parfitt et al. 2006).

The potential for obtaining and breeding foreign cultivars for characteristics that might benefit niche markets remains almost untested and unlimited. For example, some Italian varieties with small kernel size are highly favored for cooking, and are considered to have a more intense taste and a greener and more attractive kernel than 'Kerman'. In addition, consumer demand is increasing for preshelled nuts. High-yielding cultivars could probably be developed that produce only closed-shell nuts for shelling. An advantage of closed-shell nuts is that they are almost immune from attack by navel orangeworm as well as contamination by aflatoxin, both major concerns of the pistachio industry.

Other breeding objectives that appear to be within reach are cultivars that produce commercially harvestable yields at a younger age (perhaps 4th or 5th leaf instead of the current 5th or 6th leaf) and cultivars that produce larger nuts than 'Kerman' and are ready for harvest 3 to 4 weeks earlier. Genetic variability also appears to exist for alternate bearing (Kallsen et al. 2007). Some varieties have been found to begin an alternate-bearing cycle the second year that they come into bearing, as opposed to others that had not yet initiated a cycle after 7 years of bearing nuts.

'Golden Hills' and 'Lost Hills' have been planted by California pistachio growers beginning with their releases in 2005, and there may now be as many as 800 acres under cultivation. However, since pistachio does not typically bear until the 5th or 6th leaf, the first commercial production is not expected until fall 2009. No additional UC-bred varieties will be released from the trial established in 1997, but some varieties in trials established in 2002 appear to have commercial potential. Unfortunately, only a single negative characteristic can render an otherwise useful variety, with many exceptional characteristics, unsuitable for commercial production. Sometimes negative characteristics may not appear for years, so existing trials must be conducted for several more bearing cycles before it is possible to release a new cultivar.

Whether new varieties result from breeding programs in the United States or importation from overseas, scientific evaluation will remain a critical component of developing suitable and accepted cultivars for the California industry.

C.E. Kallsen is Farm Advisor, UC Cooperative Extension (UCCE), Kern County; D.E. Parfitt is Pomologist, Department of Plant Sciences, UC Davis; J. Maranto is retired Farm Advisor, UCCE Kern County; and B.A. Holtz is Farm Advisor, UCCE Madera County. Thanks to the many grower cooperators for their donations of land and labor; the California Pistachio Commission and the Pistachio Research Board for financial assistance; and Paramount Farming Company and Primex Farms for analyzing the many nut samples.

\section{References}

[CPC] California Pistachio Commission. 2007. California Pistachio Industry Annual Report, Crop Year 2006-2007. Fresno, CA. p 68.

Crane JC, Maranto J. 1988. Pistachio Production. UC ANR Pub 2279. Oakland, CA. 15 p.

Ferguson L. 2006. California Pistachio Industry. FAO CIHEAM Nucis-Newsletter 3:31-6.

Ferguson L, Maranto J, Beede R. 1995. Mechanical topping mitigates alternate bearing of 'Kerman' pis tachios (Pistacia vera L.). HortScience 30:1369-72.

Goldhamer D, Beede R. 2004. Regulated deficit irrigation effects on yield, nut quality and wateruse efficiency of mature pistachio trees. J Hort Sci Biotech 79:538-45.

Kallsen CE, Parfitt F, Holtz BA. 2007. Early differences in the intensity of alternate bearing among selected pistachio genotypes. HortScience 42:1740-3.

Parfitt DE, Chao CT, Maranto J, et al. 1996. Pistachio Cultivar Improvement 1995. California Pistachio Industry Annual Report, Crop Year 1995-96. California Pistachio Commission. Fresno, CA. p 90-8.

[USDA] US Department of Agriculture. 2007. California Agricultural Statistics, 2006 Crop Year. National Agricultural Statistics Service, California Field Office. Sacramento, CA. 96 p. www.nass.usda.gov.

Zohary D. 2006. California Pistachio Industry. FAO CIHEAM Nucis-Newsletter 3:53-5. 